\title{
De Freud a Travis. La ciudad morada se puso gris
}

\author{
From Freud to Travis. The Colorful City Turns Gray
}

\section{M arcelo Sánchez Rojel}

Universidad de Concepción. Concepción, Chile

E-mail: sanchez1@mixmail.com

\section{RESUMEN}

Para dar cuenta dela transformación radical, queva de la modernidad a la posmodernidad urbana, leemos la primera novela de Sergio Gómez V idas ejemplares en relación con la novela del mito territorial, sociológico y político que distingue a Los túneles morados de $D$ aniel Belmar. N os interesan los puntos de divergencia en tanto posibilidad de clasificar una escena literaria penquista donde opera un cambio de paradigma estético y narrativo.

Palabras claves: Ciudad, transferencia, novela moderna, relato posmoderno.

\section{ABST RACT}

In order to demonstratethe radical transformation, which goesfrom themodernity to the urban postmodern era, we read Vidas ejemplares by Sergio Gómez in relation with the novel of theterritorial, sociological and political myth that distinguishesto $D$ aniel Belmar's L ostúneles morados. We are interested in the points of difference while possibility of classifying a local literary scene where it produces change of aesthetic and narrative paradigm.

Keywords: City, transfer, modern novel, postmodern story.

Recibido: 14-04-2006. Aceptado: 01-06-2006.

Parece que nuestro destino común sea convertirnos en una película

$$
\text { PAUL VIRILIO }
$$

\footnotetext{
T REINTA y cuatro años separan a L os túneles morados (1960) y Vidas ejemplares (1994), ambas como novelas situadas en Concepción, "ciudad de la Iluvia" y "ParqueD eportivo", en el lenguajecifrado de cada autor, D aniel Belmar y Sergio G ómez, respectivamente. En esta lectura nos proponemos aplicar con-
} 
ceptos de Paul Virilio como glocalización y contaminación dromosférica; como también las aproximaciones a dos estéticas distintas: dela aparición en Bel mar y dela desaparición en Gómez; o bien, dela representación y de la mostración, de acuerdo a J ean Baudrillard y otros ensayistas contemporáneos. N uestro intento es desplegar los cambios producidos en la escritura de la ficción narrativa y la tesis de que ambos textos operan distintos imaginarios de transferencia sobre Concepción: D esde un texto que lee a la ciudad moderna y mítica, a la novela que abandona definitivamente esemito territorial, sociológico, político, esemodo de concebir y comprender la realidad y la vida'. Para escribir esta lectura utilizaremos, aunque no necesariamente en orden secuencial, los siguientes operadores de texto: C ambio de paradigma (canon europeo y suspense estadounidense); la profundidad es la piel (vida ejemplar de los 50-60 y vida ejemplar de los 8090); estilo (ética de la política y estética de la publicidad); nexos urbanos (delos bares a los medios, de la agonía existencial a la indiferencia urbana); crítica y aprendizaje versus bloqueo eincertidumbre; desacralización posmoderna (todo puede ser literatura) y, por último, de Freud a Travis: de la representación a la presentación.

$* * * *$

D eacuerdo a la teoría de las generaciones, D aniel Belmar (1906-1991) pertenecería a la llamada generación del 38 ó 42, aunque en términos de archivo local esa prescripción sea insuficiente para dar cuenta de la promoción y producción literaria desde la provincia. El autor neorrealista de Ciudad brumosa escribe antes de mayo del 68 y antes de la caída del M uro de Berlín. Vive el apogeo del realismo socialista como exportación paradigmática hacia las zonas de la intelectualidad latinoamericana comprometida con los ideales de una revolución política y cultural. Gómez escribe después del cinemascope, de M TV latina, del "Boom" latinoamericano y desde lo que más tarde será el manifiesto "M condo" - queremplaza el realismo mágico por el realismo virtual y, sobretodo, desdelos pasos irreversibles de la caída de los metarrelatos. Ambos, eso sí, quieren escribir desdela provincia, desde un punto geográfico concreto, que no correspondea la centralidad literaria nacional. Q uizás porque ambos autores proceden de ciuda-

\footnotetext{
1 Seguimos la idea general de mito propuesta por M ircea Eliade como relato de repetición y reparación. En nuestra propuesta hablamos de un momento que se pretende fundacional de la vida literaria y cultural de la ciudad, que se actualiza con unas mismas escenas cada vez que la memoria acude a esa fuente para trabajar relatos artísticos y políticos. D isfraces de la ciudad y acontecimientos propios de una conducta mítica, al borde de arquetipos argumentales como la búsqueda o anímicos como el ser tormentoso.
} 
des aún más al ejadas de núcleos metropolitanos y en esa filiación convoquen a la ciudad penquista. Belmar proviene de la zona sur argentina en un viaje de padres allende Los Andes (Temuco-N euquén-Santiago-Concepción). Gómez llega desde la zona sur chilena atraído por la promesa de estudios universitarios (casi como si fuera un personaje de la ficción belmariana²). D e cualquier manera, precisamos que el hablante nostálgico de la infancia está ausente en ambos textos.

$\mathrm{Si}$, en términos de Paul Virilio, la velocidad define el estado actual de las cosas (actual en la medida de varios años hacia atrás), los treinta años que separan a una de otra publicación hacen mayor la distancia, no sólo en cuanto anclajes de producción y recepción textual, sino también en lo que consideramos un cambio radical de paradigma. Si en Belmar predomina el canon europeo y pesa la tradición latinoamericana del huérfano (Cánovas, 1997); en Gómez asistimos al cambio que se va produciendo en el país desde la influencia política y cultural del Viejo C ontinente hacia un sostenida permeabilización dela cultura de losmassmedia capitalizada desde EstadosU nidos. Los epígrafes introductorios de Vidas ejemplares son fieles a esa adhesión. En orden lineal, el autor nos traza su mapa de preferencias. La lectura ha mutado depadres, tíos y hasta primos. Es más bien la novela norteamerican ${ }^{3}$ y el suspense cinéfilo. M e refiero a queno es la escuela francesa, ni la narrativa rusa, menos la influencia filosófica alemana. Esel inglés J oseph Conrad y losnarradoresestadounidenses Francis Scott Fitzgerald y J ohn Cheever. Los epígrafes internos son del silabario Lea, no sabemos si como metáfora del error-aprendizaje-memoria, proceso que experimentan parcialmente los protagonistas de su relato; 0 como signo denormalización (Foucault) en tanto ajuste a la sociedad por imposición molar (D eleuze), por ejemplo, de la lengua.

En su angustia de las influencias, diría $\mathrm{H}$ arold Bloom, Sergio Gómez encuentra sus fetiches en la producción cinematográfica antes que en la tradición

\footnotetext{
${ }^{2} \mathrm{~A}$ la Ciudad U niversitaria llegan "hombres y mujeres venidos desde todos los puntos del país, y aun, desde otras naciones atraídos por el sólido prestigio de sus aulas". Belmar, D aniel. 1950. Ciudad brumosa. Concepción: Edición Imprenta J.H. Salazar, p. 9.

3 Por cierto, Freud fue el héroe de Fitzgerald y su "generación perdida", queluego alimentó a Jack Kerouac para la "beat generation". Tal vez aquí sea provechosa la tesis de Fernanda Pivano: No es dadaísmo porque no le preocupa destruir mitologías o superestructuras. No es expresionismo, porque en su desconfianza ante la realidad social no afronta la política, la burguesía o el conformismo. No es surrealismo porque su negación de la supremacía racional no plantea sustituir la conciencia por el subconsciente. No es existencialismo, porque en su negación del concepto de norma no admite im perativos categóricos, ni siquiera la angustia sartreana. En “Introducción" a L ossubterrán eos(1958) de Jack Kerouac, 1998. Barcelona: Editorial Anagrama, pp. 9-25.
} 
literaria chilena, de la que explícitamente intenta escapar en una fuga que se hace más nítida al leer el manifiesto mcondian $0^{4}$. D ocumento que igualmente continúa la tradición de la ruptura tan propia de los manifiestosque dieron vida a las polémicas artísticas del siglo veinte. Sabemos, en la teoría de PierreBordieu, que la estructuración del campo literario hace movedizos a sus participantes en la búsqueda de inscripción y visibilidad. Cuando todos observan un punto fijo, basta girar la mirada para convenir una variante. En el tercer espacio de Alberto M oreiras, el escritor y la teoría latinoamericana se proponen reaccionar contra el dominio del texto metropolitano y alejarse de paradigmas identitarios y hegemónicos; se propone pensar en un intersticio entre lo hegemónico y lo subalterno. Vidasejemplaresno trabaja con la apropiación, traducción o rehistorización de textos que articulen un archivo local de experiencias literarias. Es cierto, Gómez poneen duda la esencial idad dela identidad latinoamericana, no por sospechas de utopía, sino porque su matriz conceptual se fricciona con la globalización mcondiana. En ese espacio, la profundidad esla piel. Sevive como se mira el cine.

La transición desde Belmar a Gómez opera en una condición diferente. Los túneles morados se deja influir por la escenografía teatral del ágora, del foro, del atrio, elementos tradicionales en la historia de las ciudades. Personajes, argumento, desenlaces, atmósferas, descripciones, momentos de clímax, énfasis y distintas vel ocidades escriturales texturizan los diálogos, monólogos y la voluntad omnipresente del narrador que entien de la literatura como pistas para queel lector vaya armando las historias en las páginas por venir, concentradas en tres relatos fundamentales que se desencadenan en tanto "vidas ejemplares". Aunque el texto apura sus diatribas revolucionarias, uno de los núcleos narrativos del texto verifica un pensamiento familiar: U na moral, unas costumbres, una aceptación social: EI Chico N avarro, autor de las cartas que incluye la novela, no pierde la cordura y en las vecindades de los lenocinios se avergüenza de esos "años perdidos, de este naufragio repugnante y obscuro" (151). Cierta esperanza y optimismo iluminan, al fin y al cabo, la vida: "Aquí estoy, el corazón herido pero libre. El porvenir que parecía tenebroso se ilumina a la distancia. Voy a partir. M uy lejos, hacia el sur remoto". El fracaso no hace desaparecer la certeza de tiempos mejores, apremia la duda, no la desconfianza. ¿Q ué aprenden los protagonistas de esta novela de estética alusiva5?: EI C hico N avarro, queel amor

\footnotetext{
${ }^{4}$ N os referimos a la "Presentación del País M c0 ndo", que Gómez y Alberto Fuguet escriben a manera de prólogo y manifiesto en la antología M condo, 1996. Barcelona: Editorial Mondadori.

${ }^{5}$ En la presentación del texto, Alfredo Lefebvre comenta distintos aspectos de la novela, que califica como correspondiente a la estética alusiva.
} 
con una prostituta no hace posible la familia, que es un cáncer. El O so, que la locura siempre termina en la muerte. EI C hino D omínguez, que se busca lo que nunca se encuentra, que la búsqueda del otro es siempre un viaje hacia sí mismo. La Colorina, que el exceso es autodestructivo y la ebriedad de la noche invita al crimen. Eliana, que nuestra biografía nos determina para siempre. El A buelo, que la noche tiene tratos con residuos y flujos, y que el día los "normaliza". O skar, un periodista al coholizado que termina en la cuneta, descubre la seguridad del hogar y su mujer. M artinelli, el estudiante de Leyes revolucionario, llevado a los extremos conmina al orden y asumiéndose un "intelectual podrido". A pesar de su carácter de novela residual y barrosa, admitimos en el desencanto y la marginalidad un espacio para el aprendizaje, o bien, el paso de la juventud a la madurez $z^{6}$. Los personajes cruzan de la noche al día, de la situación nómada en que recorren los bares y lenocinios de la ciudad, al sedentarismo del trabajo y la sumisión del oficio. En ese tránsito podemos hablar de escepticismo, porque el espacio del juego y la transformación quizás concluye para siempre. Confesión y conversión cierran el proceso de aprendizaje.

Las vidas de estos universitarios son ejemplares como acontece en la novela de Sergio G ómez, donde otro grupo de jóvenes asume que en la vida los ejemplos no sobran. Los dos textos trabajan con el paso de la juventud tardía (hoy, antes de los 30) a la madurez incipiente (después delos 30). El primero en torno al trance desde la universidad hacia el mundo laboral y la formación de la familia. El segundo, de los años donde todas las alternativas parecen abiertas, al momento en que es necesario decidir un futuro, un futuro distinto del aquí y ahora. ¿Q ué distancia en estas ficciones a las generaciones del 60 y del 90 ?: El discurso político, el límite de pertenencia a diferentes clases sociales, el orden disciplinario que recae sobre la conformación de L os túneles morados, cierta utopía al final del túnel, la intención nostálgica de hallar en lenocinios y bares espacios para la búsqueda de la verdad, para el sentido profundo de la existencia, de su absurdo y su miseria, de la risa y su desorden, pero también de algo más oscuro que la noche lluviosa: La incapacidad de cruzar las fronteras de la razón y la sinrazón, y salir intacto. A esa imposibilidad psicológica se suma un obstáculo material: ser pasajero o residente hace una diferencia elemental.

Siguiendo la traza baudrillariana de las ciudades modernas y posmodernas, en Gómez alternamos con la cinescenografía, es decir, mutación secuencial de una ciudad, cuya población activa se metamorfosea durante un tiempo en figurantes de una historia que conviene resucitar (Contraseñas, 1999: 42). Di-

\footnotetext{
${ }^{6}$ Algunos elementos que articulan un relato de aprendizaje son la juventud y la orfandad, el provincialismo y el viaje a la ciudad, el conflicto con la sociedad, la formación mediante experiencias vitales y la búsqueda de vocación.
} 
cho de otra manera, seres sin peso cuyo destino de atraviesa-murallas es tan enigmático como el de su última morada (55). D esaparece el discurso político, se difumina cual quier indicio de utopía y se dispersa el mito de ciudad culturalbohemia-lluviosa. M ientras la ciudad de los túneles morados es recorrida a pie en las líneas demarcadas entre centro y periferia; la ciudad que intentan habitar los personajes de la novela mcondiana no decae bajo la sombra de los márgenes. Esa dicotomía es improcedente. En la configuración urbanística, el límite delos suburbios cede terreno y ese desplazamiento lo patenta la narrativa de G ómez. También se disgrega la disposición a concitar en el relato los conflictos entre clases sociales. Se intenta menos una radiografía clásica de las diferencias, que una especie de mapa urbano de la vida diaria de unos compañeros de curso conectados por la moda o el estilo, más que por supuestas identidades locales 0 nacionales. Al target socioeconómico medio, en sus variantes alta y media, pertenecen los avatares básicos de la novela. Y como la profundidad es la piel, la cifra visible de esta condición irá instalándose en las marcas publicitarias del consumo. Si la exploración del lenguaje en Belmar quiere absorber la atmósfera Iluviosa del texto y se llena de adjetivos, de frases subordinadas, de extensas descripciones de carácter; en Gómez apreciamos una versión suficientemente mcluhaniana de acontecimientos en superficieque definen el tono y el modo de vida de los protagonistas. El cómo se ven y el cómo lo dicen dan pautas del quiénes son y qué dicen. La adjetivación deviene en objetivación. Sostenemos que esa externalización traducida en códigos visuales es propia de la cultura de la imagen y es un arreglo al lenguaje contemporáneo en que insiste la publicidad y los medios. Podríamos decir, con Lyotard, la cultura es la naturaleza, cuando la cercanía a la realidad se produce a través de la imagen. En este cruce asistimos a excesos diferentes: de adjetivar al sujeto y sus acciones, a la sustantivación de los informes descriptivos. En una técnica cercana al reportaje periodístico, el texto si guesu intención de testimoniar una época y sehacemodel o en las voces de los dosnarradores-personajes: Karen Bascuñán y Pedro Pablo Salgado. A hora (en el tiempo final del texto), bordean los 30 y hacen recuentos paralelos de sus vidas, desde los 80 hasta pasados los 90, en un repaso que se asume generacional. La música, el cine y las drogas que se consumen tienen señales precisas como los lugares que hacen posible la geografía de Concepción, ciudad bautizada por G ómez como ParqueD eportivo. Al lector se le permite reconocer las huellas citadinas: el cine D ucal (hoy desaparecido), el restorán N uria (ídem), la Galería O livieri (en la ciudad de galerías, quizá sinónimo de túneles), o bien, puntos comunes de encuentro, como "frente a Falabella" o notas propias de la memoria urbana como "el edificio con agujeros de bala del 73' (C astellón esquina $\mathrm{O}$ 'H iggins), por mencionar algunos testigos de una arquitectura insuficiente para singularizar el tránsito de ciudad. Aun así, nombres y detalles quieren esta- 
blecer que el relato "en realidad" transcurre en Concepción. Es posible reconocer un tramado, barrios característicos y una vecindad indisoluble con las comunas que conforman la provincia homónima. En este mapa cobra relevancia un rasgo natural omitido en la narrativa belmariana: el Bío-Bío, que hacia el lapso de escritura de Vidas ejemplares iniciaba su regreso triunfal a la ciudad, es decir, de cara al río, ya desprovisto de su carácter fronterizo y rediseñado por la política de infraestructura delos gobiernos de la Concertación, no sin conflictos de asentamiento y finalidad urbanística. En el texto ficticio, como es el ánimo toponímico del autor, el curso fluvial se designa como río Reunión. Este cauce, como figuración, adquiere una notable reminiscencia nerudiana. Son menos de cinco líneas en que el autor produce la psiquis del taxista pirómano, desencantado y abstraído: "A pesar dequeno veo el río Reunión por detrás del estacionamiento, siento que está ahí, fluyendo lentamente. M e siento hermanado al río involuntariamente, los dos fluimos constantemente sin detenernos" (84).

0 tra fisonomía que esbozará el contraste literario entre la ciudad de los 50 y la segunda capital chilena en términos topográficos es la presencia del mar. La provincia tiende a olvidar su esencial demarcación marítima en las novelas de Belmar, mientras que en Gómez se acerca a una configuración cinéfila, en tanto esa atmósfera suministra el cuadro que cierra la secuencia. A modo de ejemplo, citamos el interludio entre el consumo de $D$ itimil y la muerte de un personaje por exceso en la aplicación de ampollas. La escena que media entre el sueño y la conciencia es un zoom que abre la imagen: "Por una ventana abierta comienza a entrar el viento frío con olor a mar" (211). Estamos en el interior deun departamento de Remodelación Paicaví (complejo de edificios) que se convierte en sitio del suceso, en el penúltimo incendio que consuma el protagonista varón de la novela. Es cierto, la lluvia belmariana y gomecina actúan como telón de fondo, pero en el primer caso hasta devenir personaje secundario y en la segunda escritura, como esfumado, como guiño para identificar el estilo del montaje. M e explico. En Belmar, la lluvia es el flujo que reúne materias y seres dispersos 0 antagónicos. Cada vez que llueve fermenta la muerte, se remueve el barro y la razón. A veces es el "gol pe tenaz y despiadado del aguacero" (37), a veces permite evadir la realidad y a veces ser "una lluvia menuda y helada, transminante, velando el resplandor de los avisos luminosos" (27). En Gómez, la lluvia juega un rol quearticula secuencias, es la pausa o el decantador de un acontecimiento. La frase "I a ciudad está limpia después de llover toda la noche" (47) es la antesala de la violación de una menor de edad. D espués de que Pedro Pablo abusa de la hija de la nana de su madre, relata: "abro la ventana, pero afuera otra vez llueve" (51). Como los acontecimientos se presentan, más que representarse, el mal o el bien se sustraen a la adjetivación valórica. O tra escena acusa el mismo estilo: “Llueve en Parque D eportivo, pero cada vez menos (...) El río parece más 
limpio después de llover", comenta el mismo protagonista, al rato después de incendiar la residencia de los L andau (146). La serie sigue aś: : "D ecido volver al centro de la ciudad. Recorro todas las calles después de la lluvia. Veo a la gente allá afuera, los veo moverse y no me siento tan solo" (146). En tanto, la secuencia belmariana entre psiquis y paisaje es sentenciosa, afectada, no menos filosofante que adornada en la voz epistolar del Chico N avarro: "Ya no llueve. H e mirado por la ventana hacia la calle, y la niebla errante deslíe los contornos. Todo aparece moribundo, las luces, los perfiles. El tiempo pasa transformándonos (...) Pensando mejor, acaso el tiempo no fluya. Está. Somos nosotros el material informe que el tiempo conforma, perfecciona y aniquila" (145).

Incorporar a la novela anotacionesal modo como lo haceel guión teatral o el script cinematográfico, no es lo mismo que rodar esas acotaciones. Indicar no es lo mismo que filmar, resumiríamos en las sendas estrategias discursivas con que trabajan Belmar y Gómez, un novelista de la modernidad radial y un escritor de la posmodernidad visual. El autor de Coirón necesita esos comentarios para revelar la escena en tercera persona. Sus locuciones preferidas son del tipo: " $Y$ salió, a grandes tambaleos". En Gómez, la inquietud, la indecisión, siempre en primera persona sería: "C ompro una entrada en el cineD ucal, pero no entro; es decir, entro hasta el lugar donde venden chocolates y galletas y compro casi de todo lo que tienen. La vendedora no lo puede creer. D espués no logro encontrar sitio en mis bolsillos para llevarme todo" (177). Para poner en relievey precisar queno siempreen L os túnelesmoradosel alcohol es el flujo conductor del relato, el párrafo que compone la frase indica: "Lancinante punzada quemó alguna intacta región en los adentros del hombre. Pero no logró conformar el pensamiento. Sólo sintió el deseo imperioso de fugarse, evadiéndose de una realidad que se le antojó de pronto implacablemente acusadora. Salió a la calle. Y, a grandes tambaleos, se perdió en los cendales de la fina garúa" (79). Se trata de dos estilos radicalmente diferentes. Belmar pliega su texto de misterios, enunciados confesionales y culposos para desplegar un relato que quiere representar la atmósfera de cada escena, la psicología de cada personaje. Gómez despliega las voces narrativas de distintos personajes para plegar una sola complejidad y disolución. Si la novela contemporánea determina el argumento del cine, el cine condiciona el estilo del libro. Por eso es tan importante la "banda sonora" que unifica la narración gomezina. La persistencia de la música y de la cinefilia remplaza el fondo lluvioso belmariano. En la década del noventa se escribe después de la televisión y del cine, de la profusión de la FM y M TV. El coeditor de M co ndo no rehúye su tiempo. Su personaje pirómamo, después de cada incendio, se dispone a la megalomanía y la cinefilia. La influencia de la era de los medios está en los créditos que funcionan como registros de trivia. El británico Cat Stevens es la recompensa que devuelve el mundo a su normalidad, el mun- 
do de Pedro Pablo Salgado. Y si falla la música, resiste el cine. Luego de incendiar la casa de Sonia, proyecta Educando a Arizona del director de culto Joel Cohen. Cuando quema el M cVideo, regresa al hogar, se deja caer en la cama y elige Sobreviven de John Carpenter y el capítulo Scorsese de H istorias de N ueva York. Bien podrían catalogarse las películas de la vida de Pedro Pablo, en el mismo tono que acompaña el detritus lexical de moda urbana y nomenclada en Karen Bascuñán.

En otro guiño al cine, se elige una fotografía col egial para explicar qué paso con esos rostros. Es un retrato generacional: Karen es hija de padres separados, hizo su gira de estudios por Estados U nidos, regresa a vender productos Avon, se somete a un aborto y vive el fracaso del amor. Pedro Pablo es taxista, hereda la casa de sus padres, la vendey adquiere un departamento en la calle D iagonal, no oculta su carácter destructivo, consume drogas y nada parece importarle. Polo es ahora abogado, consume drogas y es pirómano. Rovira es un homosexual asumido. Sonia Tagle fue combatiente de extrema izquierda y ahora oscila entre la depresión y la decepción. Leo Rivas y Judith son profesores venidos a menos. Andrés K ol chav es un amante peregrino. Alex Landau administra las cabañas de verano de sus padres.

Los nexos que establece Gómez entre los mass media y la configuración urbana son opuestos al espacio del encierro, casi claustrofóbico y eternamente velado con que se conecta la ciudad del frío y la lluvia. Aunque la novela de Belmar transcurre una sola noche y es invierno, otros textos suyos marcan el mismo territorio y habitantes. Ciudad brumosa también se decide en los bares y Ienocinios. La "brumosa perspectiva" es su arquitectura y estética. Junto con instalar un diagrama de la ciudad (calles, bares, edificios), se propone más allá de ese diseño físico, material, la construcción de una identidad, el sello particular, un ethos penquista. La reiteración de la bruma quiere decir mucho más: "Sale a la calle borrada por la bruma" (113), "y tan sólo brumosa llovizna esfumaba las perspectivas" (66), "la ventolera agitaba la bruma" (109), "sacó la cabeza hacia la noche en actitud de avizorar la calle esfumada por el ceñido y obscuro velo de agua" (37), "la temblorosa silueta fue tragada por la líquida, brumosa perspectiva" (37), "la bruma cubría la ciudad con su opaca, impal pable mortaja" (127). La profusa adjetivación se inclina a la abundancia porque significa diluir loslímitesy es uno de los valores narrativos de Belmar. Siguiendo a Gilles D eleuze y Félix Guattari, construye episodios moleculares donde la metamorfosis del paisaje prefigura la mutación del cuerpo humano, seres que en la noche bohe-

\footnotetext{
${ }^{7}$ La sugerencia implícita parece haber sido recogida por el colega generacional de Gómez Alberto Fuguet, que años más tarde publicará Las películas de mi vida. El cine es el sustituto cultural que quiere mediar entre orfandad, ruptura, estilo y globalización.
} 
mia pierden su centro y desestabilizan las líneas de lo concebible. Estos son los fragmentos más sugerentes del texto, hasta que predomina el reordenamiento y esas figuras en tránsito se detienen anteel futuro, recapacitan, buscan y encuentran una salida. En cambio, los personajes que produce Sergio G ómez mantienen afecto por el detalle y los objetos. En su recapitulación, en ese momento inevitable del paso a otra edad, interesa menos encontrar una salida o una solución, que explorar los posibles enigmas o dar cuenta de una incertidumbre insondable. El final que cierra las páginas es más abierto en la novela de la nueva narrativa y un relato, más que otro, está supeditado al acento de la novela de aprendizaje. El Chino D omínguez, personaje central en la confección temática de Belmar, resume la experiencia del grupo de estudiantes universitarios: "No todo muere. Siempre algo sobrevive... D e otra manera no tendría objeto ni sentido la vida del hombre" (156). Karen Bascuñán, el polo cuerdo del retrato generacional de Gómez, compendia las vidas desfondadas y solitarias de un grupo de los 80 que sobrevive en los 90: "Sigo siendo la misma, pero distinta, no sési me entienden. N unca permanezco mucho tiempo en el mismo lugar. Se podría decir que evito echar raíces" (223). La ciudad que en el día recobra el "sentido de la vida" se ha desplazado hacia la no residencia, hacia "un lugar de paso, un lugar donde desde el principio se sabe que el futuro está en otra parte y no ahí (...) Ahora sé que todas las ciudades, todos los lugares, son lugares de paso" (223). La ciudad como lugar de paso no puede fundar mitos urbanos, geográficos ni políticos. Esta insistencia en la desaparición del espacio real define la estética y la arqueología de esta nueva narrativa. Todo puede suceder y puede suceder en cualquier lugar. La imagen tiempo de Gilles D eleuze (1986: 229) acierta en estehecho moderno: "Ya no creemos en este mundo. N i siquiera creemos en los acontecimientos que nos suceden, el amor, la muerte, como si sólo nos concernieran a medias. No somos nosotros los que hacemos cine, es el mundo que se nos aparece como un mal film". Karen Bascuñán - que termina lejos de Parque D eportivo- y el taxista Pedro Pablo - de quien extraviamos las pistas- habitan el espacio-velocidad que poneen contacto instantáneo distintos lugares y suplanta el espacio-tiempo de las actividades cotidianas en que maduran los universitarios de Los túneles morados. Sergio Gómez se juega por un procedimiento silencioso, a la manera en que lo entiende Paul Virilio. Es decir, instalar la fijeza de la vida en el desplazamiento. La configuración posmoderna que pretende el relato es imprecisa en los tiempos y los espacios, declinan los contactos físicos y la familia nuclear. La relación centro-periferia, tan determinante en la novela belmariana, se reordena en el texto de G ómez. Es más, desaparece en la misma velocidad con que decaeel discurso de clase que libera en el texto los conflictos de la sociedad. A patía y bloqueo son las determinantes de las vidas ejemplares. Si algo tiene sentido, es justamente ese sinsentido. Ahí sí, el 
autor de la novela hace representar un rol: M ás que presentar, convierte en divisa la indiferencia con que se mueve la generación de los 90 , generación pospolítica según los términos apropiados por el decenio siguiente.

Cambio de registro y cambio de época. La ciudad moderna que describe Belmar aún mantiene límites y necesita áreas definidas. Tanto así que las historias principales se cruzan y, más bien, desembocan en un mismo lugar: el hospital ${ }^{8}$. El narrador concibe una arquitectura para compensar la disgregación inicial y metamorfoseada con que opera la ciudad y sus habitantes. Todo ha suce dido entre la bruma o bajo la lluvia, hasta que adviene la luz del amanecer y los estudiantes de M edicina aparecen "vestidos de blanco, serios y pensativos". EI hospital despide a los muertos y también sana a los noctámbulos. La bruma parece recogerse, como lo hacen la bohemia y el trasnoche. La ciudad que inscribe G ómez no está en los bares ni en las tabernas. Su fluida conexión vial con las comunas vecinas, implica que la plaza histórica deja de ser el único centro y los espacios cerrados se amplían hacia el exterior. La ciudad como damero español no tiene un sello característico, salvo esa marca brumosa y lluviosa, propia del sur chileno, y más propia aún de esta breverelación literaria de Concepción ${ }^{9}$ : "Recorro las calles mientras llueve y el día se oscurece en mitad de la tarde (...) Veo la lluvia sobre el río Reunión. Todo está pál ido y brumoso" (115), escribe el taxista ensimismado de Vidas ejemplares. Pero la presencia de esta materialidad no tiene la fuerza asfixianteni bienhechora que trasluce la imaginería belmariana. Es cierto, la coincidencia sugiere a la vez un influjo. Es posible pensar en la influencia narrativa que ejerce Belmar o también en un sello pencopolitano en la producción literaria de la ciudad. El crítico $\mathrm{M}$ ario Rodríguez, responsable de reeditar la novela penquista del 60 , destaca la descripción naturalista de ambientes y personajes y la creación de una atmósfera que transforma las calles, la Iluvia y la ciudad en un espacio suprarreal (1999: 9). Allí las citas insistentes a la Iluvia y la bruma consolidan una especie de andamio sobre el cual escala la novela. A pasos estrechos se produce el mito de ciudad brumosa o ciudad de la Iluvia, por lo menos, es parte de la ambición literaria en tanto autoría de $D$ aniel Belmar. Es una estrategia de visibilidad e inscripción en tanto novelista de la provincia, específicamente, productor de un imaginario de transferencia. La narración no puede escapar a este proyecto. Avanzada la lectura, la voz del narrador omnipresente, que bien puede ser del mismo autor, anota un párrafo clave del ánimo de escribir y describir a C oncepción: "U na ciudad de provincia,

${ }^{8}$ El narrador es dueño de la toda la información, sostiene Rodríguez (2001: 11) en la presentación de la nueva edición de la novela.

${ }^{9}$ En esta relación profunda con la lluvia se ubican los textos narrativos (cuentos y novelas) del escritor contemporáneo de Sergio Gómez, Tito M atamala. 
en el sur, digamos. En torno a su plaza, y hasta no más allá de medianoche, se concentra el hormigueo noctámbulo. Salen los borrachitos (caballeros o pililos) debares 0 tabernas, restaurantes o boites. U nos se marchan a pie, tambal eando, expuestos a los atracos, 0 a ser cazados por los radiopatrullas. 0 tros, los menos, cogen automóviles, propios o de arriendo, y parten. A poco, sobre las calles céntricas, cae la soledad. Sólo guardias montados, un cocheque pasa, el chisporroteo vibrante y fantasmal de los avisos de neón, rompen el sosiego" (115). $M$ ás convincente, en tanto construcción de una psique urbana, resulta una de las cartas que el Chico N avarro escribe a su hermana Judith: "Cuando llegué, hace ocho años, cierto triste mediodía de invierno, un temporal golpeaba la ciudad. Las calles, los edificios, las perspectivas, todo aparecía velado, esfumándose bajo la furiosa lluvia incansable (...) A la mañana siguiente, la bruma cubría la ciudad con su opaca, impalpable mortaja. Y algo de esa impresión se replegó dentro de mí, persistiendo tenazmente, después, aún debajo del influjo tierno de las verdes primaveras y de los veranos dorados que se sucedieron" (127).

$* * * *$

En Belmar, han apreciado Alfredo Lefebvre y $M$ ario Rodríguez ${ }^{10}$, la novela interpela a un lector activo que va reuniendo las pistas como un detective. Cabe aquí la tesis del escritor y ensayista argentino R icardo Pigl ia: La narración es un arte de vigilantes, donde el lector es el detective que reúne las pruebas del crimen y una vez que logra armar el puzzle, comprendelatrama. En Sergio G ómez, la narración fragmentaria no quiere desviar la atención sobre los hechos decisivos, sobre el crimen o los sitios del suceso. Si acaso se impone un argumento, no permanece oculto bajo la ficción de la escritura a dos voces o del cambio de táctica al incluir anotaciones del tipo flaneur, porque sigue el mismo y único estilo del texto. Ciertamente, llegar al final no implica descubrir el argumento. M enos que el tema, importa el retrato. La vida está en otra parte. La desidia del estilo atestigua con la misma intensidad un crimen, un encuentro fortuito, un momento especial o una descripción citadina. En esta superación de los ideales de la vida cotidiana se producen algunas claves ideológicas del texto. En Los túneles morados, los diálogos quieren reflejar las contradicciones del sistema sociopolítico de los 60, los conflictos de clase y la emergencia del pensamiento

\footnotetext{
${ }^{10} \mathrm{~N}$ os referimos a la presentación preliminar que estos críticos hacen, respectivamente, en las ediciones dela novela fechadas en 1960 y 2001, respectivamente. El comentario de Lefebvre, hacia la fecha de lanzamiento del libro, aparece íntegramente publicado ese mismo año en las páginas del diario El Sur de Concepción.
} 
transgresor. El anarquista, el revolucionario y el escéptico conviven en la ciudad de la bruma. El estudiante de M edicina (O skar) le reprocha al estudiante de Leyes ( $M$ artinelli) su supuesta motivación revolucionaria: "No veremos nosotros la revolución... El camino es demasiado largo y difícil. Faltan hombres. El espíritu revolucionario del chileno, más romántico que estrictamentecientífico, todavía no cuaja en este frío país de poetas y radicales, de aristócratas soberbios e infelices arribistas (...) Si se presenta la oportunidad, jme vendo a la burguesía!" (30).

El retrato político de la ciudad, uno de los fondos que busca asimilar la producción literaria de Belmar, es constantey, en ese ejemplo, se hace nacional. La figura del raciocinio (el Abuelo) le replica: "N o eres precisamente un traidor, sino un resentido (...) Pero lo que acabas de decir es una solemne estupidez. $\mathrm{N} \mathrm{i}$ la pequeña burguesía de esta ciudad fenicia tendría confianza en ti, ni tú podrías aclimatarte en el servil oficio de halagarla" (31). A continuación, el coloquio se torna todavía más afectado. El Abuelo increpa al anarquista (M artinelli): "C aísteen el pozo del anarquismo, y de allí no saldrás. Tu individual ismo te condena a no traspasar las fronteras desde donde arranca la dialéctica" (31). Luego, el turno de M artinelli y su defensa; “ ¡C állate, imbécil! ¡Bajo la melena de revolucionario escondes sesos de burgués! ¿Q uién eres para calificar mi estructura ideológica?" (31).

Por supuesto, la escena es el bar y, siendo más indulgente con el autor, las décadas generosas de la oratoria, las disputas ideológicas de la lucha de clases, la guerra fría entre marxismo y capitalismo. Sergio Gómez escribe en la era global de M icrosoft y en el tiempo local posterior a la dictadura militar, después del retorno a la democracia, después del derrumbe de las ideologías tal como se conocieron en buena parte del siglo veinte. El razonamiento político es casi relegado del texto e, incluso, sobreviene antojadizo y denostado. El futuro delos 80 es el mismo de los 90, la revolución y la política son dos palabras que se cruzan en un crucigrama. La ciudad política desaparece. Nuestro protagonista posmoderno detesta a Eduardo G atti y sus melosos "M omentos", conoce a la banda The Cure y disfruta con Robert D e N iro o Tim Burton. A diferencia de Belmar, una anotación de carácter diría, por ejemplo, "yo me fui hundiendo con el sol, apagándome como una estufa a parafina" (134). Y si de política se trata, en Sonia Tagle se personifica el desencanto de la izquierda radical y en Pedro Pablo, la más absoluta indiferencia noventera: "M ientras había problemas en el país, yo aproveché de pasarlo bien" (145). Sonia, después de ser exonerada de la universidad en los ochenta (como sucedió con varios universitarios en la década de la convulsión) se aísla en el sur y regresa, años después, bajo una sombra generalizada de tendencia pospolítica y decepcionada. Pedro Pablo registra, con cierto cinismo, la pérdida de conexión con la realidad de los mitos y 
de los hitos. Resulta corrosivo cuando menciona la visita del Papa Juan Pablo Segundo a C hile y su recorrido por Concepción hacia fines de los ochenta. Así revive el momento: "M ientras el Papa hable por televisión o haga una misa, ella quiere fornicar conmigo" (170). N i inconsciente político a la manera de Fredic Jameson, ni interpretación ideológica. Colapsa la sociedad real de las clases sociales, del discurso nacional, sea de la historia como amparo del devenir, sea de las utopías modernizadoras. Los grandes relatos eclipsan. A esa transición también quiere corresponder la ficción gomecina. La idea de progreso es ambigua tanto como el eventual proceso de maduración de la generación 80-90, anclada por cierta diáspora de la voluntad.

El dominio de la sociedad de consumo, la dispersión urbana y el quiebre de las matrices modernas - como bosquejar una ciudad según su ajuste topográfico-, son consideraciones transversales de la novela. Se desvanecen los límites territoriales, porque la realidad se juega en la imagen y los signos identitarios, menos que psicológicos y políticos, se desplazan hacia las marcas publicitarias, la valoración del objeto y la estrategia de operar con dos o tres perspectivas. Por eso todo puede ser literatura. Por eso en la novela convive el origen del perfume, la etiqueta del vestuario, el catálogo de música o la mezcla de drogas. Todo es tema para la descripción. En esa especie de arqueología visual es factible clasificar a un personaje. $D$ etenerse en la moda, en los programas y películas favoritos cobra relevancia porque se ha vuelto innecesario diferenciar ideas. Sujetar la época por el consumo es inherente a la cartografía del fracaso de una zona de lo real. Es decir, apelar al "kit kat", la "negrita" o el "Rodrigo Flaño" es un signo trascendente como hito cultural de la generación. 0 stenta una carga social en tanto impresi ones de lo cotidiano y es coherente con el intercambio entre alta y baja cultura, entre conocimiento provisorio y bloqueo informático. Así se explica el libro de citas en que a ratos se convierte la novela. En esa heterogeneidad, los epígrafes de $L$ a odisea y $L$ a eneida pueden convivir con giros del conocimiento de autoayuda: "Papá hizo lo mismo que tú, cerró esos lugares que en al gún momento en la vida hay que cerrar", escribe Karen a su madre (157).

Pensamos que esta ciudad dispersa territorialmente, transitada en distintas velocidades, que se visualiza por sus fragmentos, no es menos real quela ciudad acosada por la bruma y delimitada política, social y económicamente. La ciudad glocalizada (Virilio), que conjuga los tiempos global y local, es un rasgo de la sociedad contemporánea que acerca lo lejano y aleja lo próximo. EI protagonista del texto circula, como circulan los automóviles en la carretera. No importa el horario ni la fecha. Ese nivel de realidad pierde su estatus: "N o puedo decir el mes o el día, sólo sé que es invierno" (49), "estoy en un mes que puede ser octubre o mayo" (115). El principio de inseguridad es como el más o menos y el no séquéneobarroco, cuando se reconoce lo impreciso, lo indefinido, la verdad 
multiplicada al infinito. El tiempo presentese incomunica de su aquí y ahora en favor de un sitio otro conmutativo. La presencia concreta en el mundo se convierte en telepresencia discreta en virtud de las tecnologías del tiempo real.

Y si hemos hablado de diferencias entre dos escrituras, también observamos zonas de convergencia. En ambas novelas, la ciudad es habitada entrela vida y la muerte, uno delos protagonistas fallece trágicamente, una joven mujer se somete a un aborto, uno de los personajes debe abandonar el territorio, casi no hay páginas para el humor y ambos textos incluyen cartas como ejercicios paralelos de narración. En Los túneles morados, bajo el título común de "Esa carta”, se integran en las páginas de la novela escritos que en primera persona el Chico $\mathrm{N}$ avarro quiere dirigir a su hermana. En Vidasejemplaresmadre ehija intercambian cartas, fechadas e intercaladas en la narración fragmentaria de la novela, donde a diferencia de Belmar el editor mcondiano se transporta regularmente entre el racconto y la sucesión cronológica. La necesidad de redactar cartas, práctica que tiende a la desaparición en la era cibernética, es asimilada como la urgencia de comunicar algo que no se sabe expresar en un diálogo directo con los demás (con los amigos). Esa distancia es coherente con la desolación y el conocimiento superficial que unos de otrosmantienen en Vidasejemplares, ejemplos, al parecer, de la dificultad de compartir un espacio de confianza y diálogo. Por último, en el ejercicio común por explorar un estilo, se tiende a la exageración. Belmar recargado con frases como "maldita hurañez" (145), "río después con risa verdadera" (75) o "Ios automóviles de alquiler circundaban la Plaza, esperando noctámbulos, beodos, llamadas misteriosas" (27). Gómez opta por un estilo ocioso, por ejemplo, incorporar datos del tipo reseñas de cine: "El director de la película es T im Burton, actúan entre otros Jack N icholson y Kim Bassinger" (213). La redacción es accesoria, aunque intenta funcionar con el dime lo que ves y te diré quién eres. Al igual que los epígrafes de la cultura letrada, son guiños del autor culto: más que leer a H umberto Eco para saber escribir una novela, es necesario devorar la cinematografía.

En estas glosas equivalentes nos dejamos sorprender por la única confianza del Chino D omínguez de Belmar y el epílogo de la novela: “Saben qué? Está lloviendo". 0 bien, repetimos con Pedro Pablo: "La lluvia arrastrará el frío y todos nos sentiremos mejor en Parque D eportivo". En sus procesos de visualización e inscripción, Belmar mira en la provincia un rescate de los márgenes, produciendo el mito de ciudad bohemia, transgresora y cultural, pero no desde la estructuración marxista del conflicto burguesía versus proletariado. La expe riencia narrativa da cuenta de la periferia como sitio de conocimiento, porque sus protagonistas cruzan geografía y experiencia al tensionar los puntos difusos de la urbe. Sergio Gómez encara otro modelo, lo interpela y decide operar con otro imaginario, acorde con el desafío de ópera prima. La ciudad deja de estar 
en la provincia y puede ser cualquiera, cualquiera que parezca globalizada. En esta y otras direcciones hemos cifrado el traspaso de Freud a Travis. Los arquetipos del psicoanálisis, la ilustración y el pensamiento disciplinario abruman gran parte de la maquinaria narrativa de Los túneles morados, especialmente en el complejo de Edipo del escritor de las cartas que incluye el texto. El Chico $\mathrm{N}$ avarro, que termina enamorándose de una prostituta, relata su iniciación sexual con una mujer madura que marca para siempre su vida: "M i adolescencia se quebró entre los flacos muslos de la tía M ercedes" (82). Los diálogos, la revolución, el archivo local en que pretende transformarse el texto como documento urbano, se inscriben en el panorama de ciudad bohemia, intelectual, de grupos cohesionados y espacios cerrados. U no de los valores que concentra el texto, en una lectura postestructuralista, es su opción por situarse en los espacios fronterizos del prostíbulo y los bares, además de concebir a personajes que "no tienen pasado ni futuro, sólo tienen devenires" (Rodríguez 2001: 5-18). ¿Logran estas fronteras constituir una ciudad, un tiempo, unos habitantes? ¿Acaso sendasnove las definen un archivo para documentar una época, traicionar un mito o la arbitrariedad de sus hitos culturales? ¿Es más real Concepción como ciudad brumosa o como parque deportivo, como ficción lluviosa o como incidente urbano?

H emos imaginado a Pedro Pablo, como quizás selo imaginó el propio escritor Sergio Gómez, como Travis, el complejo einestable personaje de Taxi D river (1976) interpretado por D e N iro para el cineasta M artin Scorsese. En la versión local es un flaneur contemporáneo que en el espacio-velocidad recorre en taxi las calles de Parque D eportivo y sus al rededores. El autor de la novela deja en cursivasy en columnas reducidas los diez apuntesurbanos dePedro Pablo Sal gado, pero sigue el mismo registro de los demás párrafos, tampoco difiere del tono que mantiene la otra narradora protagonista del relato. Si bien el autor promueve una distancia de sí al producir dos narradores, el modo y el tono son menos ambiguos. Respecto de los apuntes, el taxista nos describe, por ejemplo, cuando en Freire con Paicaví observa a "un tipo muerto en la calle" (171-172), cuando "la calle está llena de gente extraña. G ente fea y amenazadora" (48-49), cuando se reencuentra con un personaje del pasado queluego desangra enterrándole un tenedor en los testículos (191-202), cuando un "tipo y su sobrina" salen del motel Fish (206). "La gente es extraña" (208) reitera en su último apunte y lo dice un pirómano, ahora homicida y con una adhesión desbordante por encontrar más vida en el cine y la música que en la realidad. Se quiere escribir el lado B, el lado de los perdedores, el lado de Karen Bascuñán y de Pedro Pablo, un anverso del love story. "Tenía metido en la cabeza que los perdedores éramos los buenos" (176-177), exclama el taxista. En cambio, para Belmar la interpretación de los sueños o el materialismo dialéctico se dejan sentir en al gunas texturas. Sólo para enfatizar: "El espíritu revolucionario del chileno (...) todavía no 
cuaja en este frío país de poetas y radicales, de aristócratas soberbios e infelices arribistas". Con Sergio Gómez, mucho después de la imposibilidad revolucionaria y a propósito de la dictadura militar chilena, se aprecia una insuficiencia similar, pero la razón se transforma cardinalmente: "Todo ocurrió demasiado rápido y nadie estaba preparado" (162). Esa frase se puede digerir en la sala oscura de un cine 0 en el lenguaje cotidiano de la calle. En verdad, lo intensamente fatal para Pedro Pablo es la ausencia de imagen en la pantalla del televisor, no el incendio ni el asesinato: "M e echo en la nariz un poco de cocaína (...) M e siento en la silla del dormitorio y enciendo el televisor, pero a esa hora no hay nada" (212). Inercia polar ${ }^{11}$. Estado de sitio domiciliario, por la llegada generalizada de imágenes y sonidos. En este paso del aquí por el ahora, "el dispositivo tele reemplaza el espacio público por la imagen pública y la imagen pública está descentrada de la ciudad. La imagen pública no está en la ciudad, 0 en la tele-cittá, ciudad virtual ya, en la que se pretende convivir porque miran juntos el informativo televisivo. Creo que lo que se cuestiona tras el problema del espacio virtual es la pérdida de la ciudad real" (Virilio, 1999: 47). Internet y los puertos electrónicos tienden a urbanizar el tiempo real en el momento en que se desurbaniza el espacio real (48). En la ciudad de los túneles morados, del atrio y del foro, el contacto es próximo. En la ciudad de las autopistas electrónicas y asfálticas, tiende a desaparecer. La ecología gris, la ecología de las distancias, no se aprecia porque no es visible sino mental. La forma urbana cambia o se transforma, como las plazas techadas (los mall), donde la vida cívica apela a otro contacto, a un poder y unaimagen deintercambio. "La cuestión del prójimo y del alejado, es la cuestión de la ciudad" (43), observa el urbanista francés, al tiempo quevaticina que la solución dela velocidad y la virtualidad es la reorganización del lugar de vida en común (51-54), una regresión al término político de la polis.

En la novela de Gómez persiste la sensación de inestabilidad de los seres humanos y la fugacidad de las cosas. La novel a experimenta una contaminación dromosférica, una contaminación de la dimensión real por la velocidad. Es un relato como contraseña de época, una versión posible y global de generación $X$, donde más que experiencias intelectuales o ideológicas priman las experiencias prácticas o mecánicas. Ahí se juega la intensidad de la vida, sin arquetipos, sin héroes ni antihéroes. Esa arqueología urbana sin territorio es la estética ${ }^{12}$ del

\footnotetext{
${ }^{11}$ Esta es la consecuencia de la era de los medios, de la cultura de la imagen, de acuerdo a Paul Virilio (1999: 29).

${ }^{12}$ Es sugerente "El efecto de empequeñecimiento" de quehabla Paul Virilio (1996: 45-70): "Con la aceleración ya no hay el aquí y el allá, sólo la confusión mental de lo cercano y lo lejano, el presente y el futuro, lo real y lo irreal, mezcla de historia, las historias y la utopía alucinante de las técnicas de la comunicación".
} 
autor. Por eso la ciudad narrada o ficticia alcanza delgadamente un paralelo inmediato, local izado, con la ciudad real. La complejidad demográfica, socioeconómica, política o cultural del mapafísico permaneceintacta. M ás bien, insistimos, se trata de un tiempo, una edad que intenta actualizarse y en ese proceso, desmitificarse. Poner al día, por ejemplo, inflexiones temáticas: A parece una voz femenina (un autor hombre escribe como mujer); la familia nuclear se divorcia; la prostitución infantil no se desarrolla, pero se memoriza en una escena rugosa; el consumo de drogas es también tema; setonifica la sexualidad como placer (en Belmar resulta matriz de represiones y pulsiones fatales); y en la desidia de los diálogos y esa voz en off que parece discurrir a lo largo del texto manifiesta su total prescindencia del debate político (como se entendió por lo menos hasta los 80). Q uizás por ello, el discurso de D aniel Belmar se pueda repasar como letrado y comprometido. En los personajes de Sergio Gómez se anula el conocimiento pedagógico y prevalece una especie de confinamiento por el extravío del espacio real. Lo que en L ostúneles morados se vive como plaza y suburbios, en el relato de la nueva narrativa se desplaza hasta disiparse completamente, desaparece el reticulado urbano y su eje divisorio. La pérdida de centro hacela diferencia. La ciudad moderna de indicios locales deviene hoy ciudad interconectada sin denominación de origen, porque esa memoria deja de tener importancia.

\section{REFERENCIAS}

Belmar, D aniel. 1960. Los túneles morados. Santiago, C hile: Editora Zig-Zag. ----- . 1950. Ciudad brumosa. Concepción, Chile: Imprenta J. H. Salazar. Baudrillard, Jean. 2002. Contraseñas. Barcelona: Editorial Anagrama.

-----1 . 1994. Dela seducción. Buenos Aires: Red Editorial Iberoamericana.

Cánovas, Rodrigo. 1997. N ovela chilena, nuevas generaciones, el abordaje delos huérfanos. Santiago, Chile: Ediciones U niversidad Católica de Chile.

Deleuze, Gilles. 1986. La imagen tiempo. Barcelona: Paidós.

D eleuze, Gilles y Guattari, Félix. 1997. M il mesetas. C apitalismo y esquizofrenia.

Valencia: Pre-Textos.

Fuguet, Alberto y Gómez, Sergio. 1996. M condo. Barcelona: Editorial M ondadori.

Gómez, Sergio. 1994. Vidas ejemplares. Santiago, C hile: Editorial Planeta.

Goic, Cedomil. 1968. La novela chilena. Los mitos degradados. Santiago, Chile: Editorial Universitaria.

Jameson, Fredic. 1989. D ocumentos decultura, documentos debarbarie M adrid: Visor. M oreiras, Alberto. 1999. Tercer espacio: Literatura y duelo en América Latina. Santiago, Chile: Lom-Universidad Arcis.

Virilio, Paul. 1996. El arte del motor. Aceleración y realidad virtual. Buenos Aires: Editorial M anantial.

- - - - . 1997. La velocidad de la liberación. Buenos Aires: Editorial M anantial. 
De Freud a Travis. La ciudad morada se puso gris / M. SÁnchez R.

- - - . 1999a. La inercia polar. M adrid: Trama Editorial.

- - - . 1999b. "La pérdida del mundo o cómo reencontrarse el cuerpo propio". En El cibermundo, la política de lo peor, pp. 41-69. M adrid: Ediciones Cátedra. - - - - . 2003. El procedimiento silencio. Buenos Aires: Paidós. 